\title{
Differential susceptibility on myosin heavy chain isoform following eccentric-induced muscle damage
}

\author{
Seung Jun Choi* \\ Division of Sports and Health Science, Kyungsung University, Busan, Korea
}

Based on myosin heavy chain (MHC) isoform, human skeletal muscle fibers can be categorized into three fiber types, type I, Ila, Ilx fibers, and each fiber type has different characteristics. Typical characteristics are difference in force production, shortening velocity, and fatigue resistance. When the muscle is contract and stretched by a force that is greater than the force generated by the muscle, contraction-induced muscle damage frequently occurs. Several experimental models involving both human and animal have considered the susceptibility of different muscle fiber type and part of muscles to eccentric induced muscle damage. General consensus is a greater susceptibility of fast-twitch fi- ber or type II fiber to damage following eccentric contractions. However, the results from these previous efforts were not enough to conclude the susceptibility between each individual fiber types after eccentric contraction. Therefore, the purpose of this review is to explore detail limitation and interpretation of previous studies, and review the recent study that eliminated the prior limitations, such as strain magnitude, lengthening velocity, fiber type heterogeneity, and muscle architecture issue.

Keywords: Myosin heavy chain, Fiber type, Eccentric contraction, Single fiber

\section{INTRODUCTION}

Muscle is a heterogeneous tissue, containing cells with different contractile properties, metabolic profiles, and fatigue resistance. Much of this diversity is correlated with the myosin heavy chain (MHC) isoform expressed by the cell. Small mammals express nine MHC isoforms of which four, type I or $\beta$, type IIa, type IIx, and type IIb, are expressed in adult limb muscles (Ennion et al., 1995; Smerdu et al., 1994). The type IIb isoform is not found in the limb muscles of large mammals, including humans. Human muscle fibers can be categorized into three fiber types: type I, IIa, and IIx (Ennion et al., 1995; Smerdu et al., 1994). These isoform can also be co-expressed, resulting in hybrid fiber types: type I/Ila, and type IIa/IIx or even type I/IIa/IIx (Caiozzo et al., 2003; Pette and Staron, 2001). Typical characteristics of fiber types are force production, and shortening velocity. Type IIa or IIx fiber produce higher force and contract faster than type I fibers, whereas type I fibers appear to be more fatigue resistant than other fiber types. Type IIx fiber contract and relax slightly faster than type IIa fibers, but both are faster than type I fiber.

As well known, an eccentric contraction is much more likely to injury a muscle compared to an isometric contraction or a contraction in which the force producing muscle shortens (Allen, 2001; Faulkner et al., 1993; Lieber and Friden, 2002; Proske and Allen, 2005; Warren et al., 2001). It is also generally accepted that fast muscle fibers are more susceptible to eccentric contraction than slow muscle fibers (Friden et al., 1983; Jones et al., 1986; Lieber and Friden, 1988; Warren et al., 1994). This idea is based on histological and functional experiments performed on human and animal models. However, a critical appraisal of this body of work shows that the evidence supporting the idea that fast muscle fibers are more susceptible to eccentric injury is far from complete or conclusive. Therefore, in this review the detail limitation of previous work on distinct susceptibility on MHC isoform will be discussed first, and then recent work on differential susceptibility of MHC heterogeneity will be reviewed.
${ }^{*}$ Corresponding author: Seung Jun Choi

Division of Sports and Health Science, Kyungsung University, 309 Suyoung-ro,

Nam-gu, Busan 608-736, Korea

Tel: +85-51-663-4955, Fax: +82-51-663-4956, Email: choisj@ks.ac.kr

Received: November 12, 2014 / Accepted: November 17, 2014
This is an Open Access article distributed under the terms of the Creative Commons Attribution Non-Commercial License (http://creativecommons.org/licenses/by-nc/3.0/) which permits unrestricted non-commercial use, distribution, and reproduction in any medium, provided the original work is properly cited. 


\section{PREVIOUS STUDIES IN DISTINCT SUSCEPTIBILITY ON MHC ISOFORM}

Studies on humans have reported a greater susceptibility of fasttwitch fibers to damage (Asp et al., 1998; Friden et al., 1983; Jones et al., 1986). However, these studies have used indirect methods to quantify the muscle injury such as histological markers of damage (Friden et al., 1983) or the plasma creatine kinase (CK) concentration (Jones et al., 1986). Plasma CK concentration is frequently used as an index of the muscle damage after eccentric contraction. However, no significant correlation was observed between CK concentration and muscle strength (Friden and Lieber, 2001). Another study investigated muscle glycogen content after eccentric exercise, and it revealed type II fibers were predominantly recruited (Asp et al., 1998). Thus the authors concluded a selective effect of eccentric contractions on type II fiber but it could not be readily accepted that the glycogen content represents the susceptibility of muscle structure and functional to damage.

Functional approaches performed on isolated mouse muscle (soleus and extensor digitorum longus (EDL)) are limited by fiber type heterogeneity and muscle architectural differences. For instance, mouse soleus muscles are not constituted with only slow fiber types, and mouse EDL muscle express an extra MHC isoform, type IIb, which is not founded in human limb muscle (Ennion et al., 1995; Smerdu et al., 1994). Furthermore, its slow type I MHC isoform has a faster velocity than the human slow type I MHC (Widrick et al., 1997). Thus, these species differences could confound generalization of animal data to humans. Also, the differences of muscle architecture between mouse soleus and EDL muscle resulted in the differentiation of applied strain amount to each muscle, due to differences in the fiber length to muscle length ratios of these muscles (Warren et al., 1994).

Studies using single muscle fibers, obtained from animals report that muscles comprised of predominantly fast fibers are preferentially damaged (Brockett et al., 2002; Friden and Lieber, 1992; Lieber and Friden, 1988; Lynch et al., 2008; Macpherson et al., 1996; Rader et al., 2007; Vijayan et al., 2001). Only three of these studies have directly examined muscle fiber function: two studies examined fibers from the predominately slow soleus and the predominately fast EDL of the rat (Lynch et al., 2008; Macpherson et al., 1996), and another study examined fibers from normal and congenitally clefted goat palates (Rader et al., 2007). Most of these studies have been performed using muscles from rodents. As discussed above, small mammals and humans do not express all of the same MHC isoforms. Sarcomere heterogeneity after eccentric con- tractions was also measured with fiber type identification by sodium dodecyl sulfate polyacrylamide gel electrophoresis (SDS-PAGE) (Patel et al., 2004). However, they used the pooled fiber bundles from the frog tibialis anterior muscle, which is comprised of two equal part of fastest amphibian muscle fiber type (Lutz et al., 1998). Brockett (Brockett et al., 2002) also studied the vulnerability of different motor units that consisted of mixed fiber types using the cat muscle without identifying the fiber types. None of these studies examined MHC isoform content and function in the same fibers, making it difficult to draw conclusions about damage to individual fiber types.

Although most studies show greater susceptibility of fast-twitch fibers, a few studies report that slow-twitch, or type I fibers, were selectively damaged during eccentric contractions. Armstrong (Armstrong et al., 1983) showed that the deeply embedded slowtwitch fibers were predominantly damaged after downhill running compare to level running. However, downhill running may preferentially recruit the slow fiber type, and this may obscure which type is actually more susceptible. Another study indicated the increased fragment rate in slow-twitch skeletal MHC through magnetic resonance imaging (Mair et al., 1992), and plasma creatine kinase $(\mathrm{CK})$ concentration, which is not a highly correlated index of muscle damage.

\section{POTENTIAL MECHANISM OF PREFERENTIAL DAMAGE TOFAST TWITCH MUSCLE AFTER ECCENTRIC CONTRACTION}

Even though there is no conclusive mechanism yet, several potential mechanisms were proposed to explain the greater vulnerability of fast-twitch fibers. One proposed mechanism was that fasttwitch fibers fatigued faster than slow-twitch fiber, and the fasttwitch fibers stay in rigor binding stage during cross-bridge cycle due to impaired ATP regeneration, which results in mechanical damage as these rigor fibers are stretched (Friden and Lieber, 1992). However, this hypothesis does not hold up because studies report that fatigued muscle is less susceptible to damage or fatigue has no effect (Choi and Widrick, 2009; Friden and Lieber, 1992; Mair et al., 1996; Morgan et al., 2004) and other studies support the fatigued muscle is more resistible to eccentric-induced muscle injury (Nosaka and Clarkson, 1997). It has been suggested that the ultrastructural differences between type I and type II fibers explain the greater vulnerability of fast-twitch fibers to eccentric-induced muscle damage. Fast-twitch fibers have narrower Z-lines compared to slow-twitch fibers (Friden et al., 1983), which reflect fewer at- 
tachments for thick and thin filaments (Yamaguchi et al., 1985). Type II fibers contain smaller isoforms of the sarcomeric proteins myomesion and nebulin, which play a role in sarcomere assembly (Agarkova et al., 2004; Prado et al., 2005). Therefore, relatively greater stress is applied to the cytoskeleton of fast fiber, resulting in a higher susceptibility to damage. This phenomenon also confirmed from the reloaded human soleus fiber after 17 days of bed rest and spaceflight (Widrick et al., 1999). He found that the fibers, have weak connections between sarcomeres were relatively weaker than fibers, have normal connection between sarcomeres, due to greater workload. Also, fast fibers express a lower molecular weight, and less elastic, titin isoform than slow fibers (Prado et al., 2005) The less compliant titin in fast fibers may transmit greater stress during eccentric contractions (Horowits, 1992).

Accordingly, it is widely accepted that fast-twitch, or type II fibers tend to be more vulnerable to eccentric-induced muscle injury (Byrne et al., 2004; Proske and Morgan, 2001). However, none of above studies has investigated the relationship between fiber MHC isoform content and its susceptibility to eccentric contraction using single fiber preparation, isolated from human muscle, with the identification of fiber type.

\section{RECENT STUDIES IN DISTINCT SUSCEPTIBILITY ON MHC ISOFORM}

Accordingly, it is clear that more data examining the relationship between fiber type expression and susceptibility after eccentric contraction are required. Chemically skinned single muscle fiber preparations can avoid limitations of previous studies by allowing the investigator control over strain magnitude and velocity under standard experimental conditions of temperature, ionic strength and activating $\mathrm{Ca}^{2+}$ concentration. The issue of fiber type heterogeneity can also be overcome by identification of $\mathrm{MHC}$ isoforms in the same of single muscle fiber segments used for the physiological assays.

There is a study that utilizes the single fiber approach to examine the differential susceptibility on MHC isoform (Choi and Widrick, 2010). $\mathrm{Ca}^{2+}$-activated skinned muscle fiber segments, prepared from healthy untrained young subjects $(25 \pm 2 \mathrm{yr}, \mathrm{n}=10)$ were subjected to standardized an eccentric contraction, in terms of strain magnitude (25\% of fiber length) and lengthening velocity ( $50 \%$ of maximum shortening velocity). Maximal force was measured before and after a single eccentric or fixed-end contraction, and fiber MHC isoform contents were confirmed by gel electrophoresis. A model was developed using multiple linear regression to describe how each of major fiber type populations present in human limb muscle responds to a single eccentric contraction, The best model reveals a fiber type independent factor (pre-treatment force) and a fiber type dependent factor (MHC expressions) to the damage process. Regardless of fiber type, fiber generating greater pre-eccentric specific force showed greater post-eccentric force deficits. When this pre-treatment force was controlled, fiber expressing type I or IIa MHC had identical force change to the eccentric contraction, whereas fiber co-expressing the type IIa and IIx MHC isoforms showed 3-folder greater force deficit. These results could be interpreted as evidence that the fastest MHC isoforms, in this case type IIx, were associated with greater damage. However, an equally valid interpretation would be that the co-expression of multiple MHC isoforms within the same fiber is the critical factor. Note

However, a limitation of the skinned fiber approach is that fibers are studied in an artificial milieu (although one thought to represent the intracellular milieu). In addition, the skinning process may remove or allow efflux of structural (e.g. dystrophin) or enzymatic (e.g. calpain) proteins that may be involved in the damage process. Finally, fibers are maximally activated where in vivo, different fiber types may be differentially recruited by the nervous system, altering their apparent susceptibility to injury. Therefore, additional studies need to address the response of living cells to in vivo eccentric exercise.

\section{CONCLUSIONS}

While most studies conclude that type II fibers are more susceptible to eccentric-induced muscle injury, these finding are based on indirect measures of damage, conducted on muscles instead of fibers, and if conducted on fibers, have not confirmed MHC isoform context by gel electrophoresis which provide a more accurate determination of the fiber types including hybrid fiber (Glaser et al., 2010; Pandorf et al., 2010). Since most muscles are heterogeneous in the fiber type composition, whole muscle or motor unit studies cannot effectively evaluate changes of function occurring in type I and type II fibers following eccentric contractions. However, recent single muscle fiber study found a single eccentric treatment (25\% strain with $50 \%$ lengthening velocity) resulted in $9 \mathrm{kN} / \mathrm{m}^{2}(8.1 \%)$ and $12 \mathrm{kN} / \mathrm{m}^{2}(9.8 \%)$ of force drop compare to pre-treatment force for fibers expressing a single MHC isoform (I and IIa, respectively). However, hybrid fibers containing IIa and IIx MHC isoform showed 3-folders greater force deficit $\left(38 \mathrm{kN} / \mathrm{m}^{2}, 28.4 \%\right)$ than either type I or type Ila fibers. These results indicate that human fast 
hybrid fibers (IIa/IIx) are further sensitive to a standardized in vitro eccentric contraction.

\section{CONFLICT OF INTEREST}

No potential conflict of interest relevant to this article was reported.

\section{ACKNOWLEDGMENTS}

This research was supported by Kyungsung University Research Grants in 2014.

\section{REFERENCES}

Agarkova I, Schoenauer R, Ehler E, Carlsson L, Carlsson E, Thornell LE, Perriard JC. The molecular composition of the sarcomeric m-band correlates with muscle fiber type. Eur J Cell Biol 2004;83:193-204.

Allen DG. Eccentric muscle damage: Mechanisms of early reduction of force. Acta Physiol Scand 2001;171:311-319.

Armstrong RB, Ogilvie RW, Schwane JA. Eccentric exercise-induced injury to rat skeletal muscle. J Appl Physiol 1983;54:80-93.

Asp S, Daugaard JR, Kristiansen S, Kiens B, Richter EA. Exercise metabolism in human skeletal muscle exposed to prior eccentric exercise. J Physiol 1998;509 (Pt 1):305-313.

Brockett CL, Morgan DL, Gregory JE, Proske U. Damage to different motor units from active lengthening of the medial gastrocnemius muscle of the cat. J Appl Physiol 2002;92:1104-1110.

Byrne C, Twist C, Eston R. Neuromuscular function after exercise-induced muscle damage: Theoretical and applied implications. Sports Med 2004;34:49-69.

Caiozzo VJ, Baker MJ, Huang K, Chou H, Wu YZ, Baldwin KM. Single-fiber myosin heavy chain polymorphism: How many patterns and what proportions? Am J Physiol Regul Integr Comp Physiol 2003;285: R570580.

Choi SJ, Widrick JJ. Combined effects of fatigue and eccentric damage on muscle power. J Appl Physiol 2009;107:1156-1164.

Choi SJ, Widrick JJ. Calcium-activated force of human muscle fibers following a standardized eccentric contraction. Am J Physiol Cell Physiol 2010;299:C1409-1417.

Ennion S, Sant'ana Pereira J, Sargeant AJ, Young A, Goldspink G. Characterization of human skeletal muscle fibres according to the myosin heavy chains they express. J Muscle Res Cell Moti 1995;16:35-43.

Faulkner JA, Brooks SV, Opiteck JA. Injury to skeletal muscle fibers during contractions: Conditions of occurrence and prevention. Phys Ther 1993;
73:911.

Friden J, Lieber RL. Structural and mechanical basis of exercise-induced muscle injury. Med Sci Sports Exerc 1992;24:521-530.

Friden J, Lieber RL. Serum creatine kinase level is a poor predictor of muscle function after injury. Scand J Med Sci Sports 2001;11:126-127.

Friden J, Sjostrom M, Ekblom B. Myofibrillar damage following intense eccentric exercise in man. Int J Sports Med 1983;4:170-176.

Glaser BW, You G, Zhang M, Medler S. Relative proportions of hybrid fibres are unaffected by 6 weeks of running exercise in mouse skeletal muscles. Exp Physiol 2010;95:211-221.

Horowits R. Passive force generation and titin isoforms in mammalian skeletal muscle. Biophys J 1992;61:392-398.

Jones DA, Newham DJ, Round JM, Tolfree SE. Experimental human muscle damage: Morphological changes in relation to other indices of damage. J Physiol 1986;375:435-448.

Lieber RL, Friden J. Selective damage of fast glycolytic muscle fibres with eccentric contraction of the rabbit tibialis anterior. Acta Physiol Scand 1988;133:587-588.

Lieber RL, Friden J. Mechanisms of muscle injury gleaned from animal models. Am J Phys Med Rehabil 2002;81:S70-79.

Lutz GJ, Cuizon DB, Ryan AF, Lieber RL. Four novel myosin heavy chain transcripts define a molecular basis for muscle fibre types in rana pipiens. J Physiol 1998;508 ( Pt 3):667-680.

Lynch GS, Faulkner JA, Brooks SV. Force deficits and breakage rates after single lengthening contractions of single fast fibers from unconditioned and conditioned muscles of young and old rats. Am J Physiol Cell Physiol 2008;295:C249-256.

Macpherson PC, Schork MA, Faulkner JA. Contraction-induced injury to single fiber segments from fast and slow muscles of rats by single stretches. Am J Physiol 1996;271:C1438-1446.

Mair J, Koller A, Artner-Dworzak E, Haid C, Wicke K, Judmaier W, Puschendorf B. Effects of exercise on plasma myosin heavy chain fragments and mri of skeletal muscle. J Appl Physiol 1992;72:656-663.

Mair SD, Seaber AV, Glisson RR, Garrett WE. The role of fatigue in susceptibility to acute muscle strain injury. Am J Sports Med 1996;24:137.

Morgan DL, Gregory JE, Proske U. The influence of fatigue on damage from eccentric contractions in the gastrocnemius muscle of the cat. J Physiol 2004;561:841-850.

Nosaka K, Clarkson PM. Influence of previous concentric exercise on eccentric exercise-induced muscle damage. J Sports Sci 1997;15:477-483.

Pandorf CE, Caiozzo VJ, Haddad F, Baldwin KM. A rationale for sds-page of mhc isoforms as a gold standard for determining contractile phenotype. J Appl Physiol 2010;108:222-222.

Patel TJ, Das R, Friden J, Lutz GJ, Lieber RL. Sarcomere strain and heterogeneity correlate with injury to frog skeletal muscle fiber bundles. J 
Appl Physiol 2004;97:1803-1813.

Pette D, Staron RS. Transitions of muscle fiber phenotypic profiles. Histochem Cell Biol 2001;115:359-372.

Prado LG, Makarenko I, Andresen C, Kruger M, Opitz CA, Linke WA. Isoform diversity of giant proteins in relation to passive and active contractile properties of rabbit skeletal muscles. J Gen Physiol 2005;126: 461-480.

Proske U, Allen TJ. Damage to skeletal muscle from eccentric exercise. Exerc Sport Sci Rev 2005;33:98-104.

Proske U, Morgan DL: Muscle damage from eccentric exercise: Mechanism, mechanical signs, adaptation and clinical applications. J Physiol 2001;537:333-345.

Rader EP, Cederna PS, Weinzweig J, Panter KE, Yu D, Buchman SR, Larkin LM, Faulkner JA. Contraction-induced injury to single permeabilized muscle fibers from normal and congenitally-clefted goat palates. Cleft Palate Craniofac J 2007;44:216-222.

Smerdu V, Karsch-Mizrachi I, Campione M, Leinwand L, Schiaffino S. Type iix myosin heavy chain transcripts are expressed in type iib fibers of human skeletal muscle. Am J Physiol 1994;267:C1723-1728.
Vijayan K, Thompson JL, Norenberg KM, Fitts RH, Riley DA. Fiber-type susceptibility to eccentric contraction-induced damage of hindlimb-unloaded rat al muscles. J Appl Physiol 2001;90:770-776.

Warren G, Hayes D, Lowe D, Williams J, Armstrong R. Eccentric contraction-induced injury in normal and hindlimb-suspended mouse soleus and edl muscles. J Appl Physiol 1994;77:1421-1430.

Warren GL, Ingalls CP, Lowe DA, Armstrong RB. Excitation-contraction uncoupling: Major role in contraction-induced muscle injury. Exerc Sport Sci Rev 2001;29:82-87.

Widrick JJ, Knuth ST, Norenberg KM, Romatowski JG, Bain JL, Riley DA, Karhanek M, Trappe SW, Trappe TA, Costill DL, Fitts RH. Effect of a 17 day spaceflight on contractile properties of human soleus muscle fibres. J Physiol 1999;516 (Pt 3):915-930.

Widrick JJ, Romatowski JG, Karhanek M, Fitts RH. Contractile properties of rat, rhesus monkey, and human type i muscle fibers. Am J Physiol 1997;272:R34-42.

Yamaguchi M, Izumimoto M, Robson RM, Stromer MH. Fine structure of wide and narrow vertebrate muscle z-lines. A proposed model and computer simulation of z-line architecture. J Mol Biol 1985;184:621-643. 